\title{
CATALYTIC EXTRACTION PROCESSING OF CONTAMINATED SCRAP METAL
}

\section{DISCLAIMER}

Author:

Thomas P. Griffin

James E. Johnston

Contractor:
This report was prepared as an account of work sponsored by an agency of the United States Government. Neither the United States Government nor any agency thereof, nor any of their employees, makes any warranty, express or implied, or assumes any legal liability or responsibility for the accuracy, completeness, or usefulness of any information, apparatus, product, or process disclosed, or represents that its use would not infringe privately owned rights. Reference herein to any specific commercial product, process, or service by trade name, trademark, manufacturer, or otherwise does not necessarily constitute or imply its endorsement, recommendation, or favoring by the United States Government or any agency thereof. The views and opinions of authors expressed herein do not necessarily state or reflect those of the United States Government or any agency thereof.

Molten Metal Technology, Inc.

51 Sawyer Road

Waltham, MA 02154

\section{Contract Number:}

DE-AC21-93MC30171

\section{Conference Title:}

Opportunity '95 - Environmental Technology Through

Small Business

\section{Conference Location:}

Morgantown, West Virginia

\section{Conference Dates:}

November 16 - 17, 1994

\section{Conference Sponsor:}




\section{DISCLAIMER}

Portions of this document may be illegible in electronic image products. Images are produced from the best available original document. 


\subsection{Catalytic Extraction Processing of Contaminated Scrap Metal}

\section{CONTRACT INFORMATION}

Contract Number

Contractor
DE-AC21-MC30171

Molten Metal Technology, Inc.

51 Sawyer Road

Waltham, MA 02154

(617) 487-7681
Contractor Project Manager

Principal Investigators

METC Project Manager

Period of Performance Schedule and Milestones
Brian M. Payea

Thomas P. Griffin, Sc.D.

James E. Johnston, Sc.D.

William J. Huber

September 30, 1993, to February 28, 1995

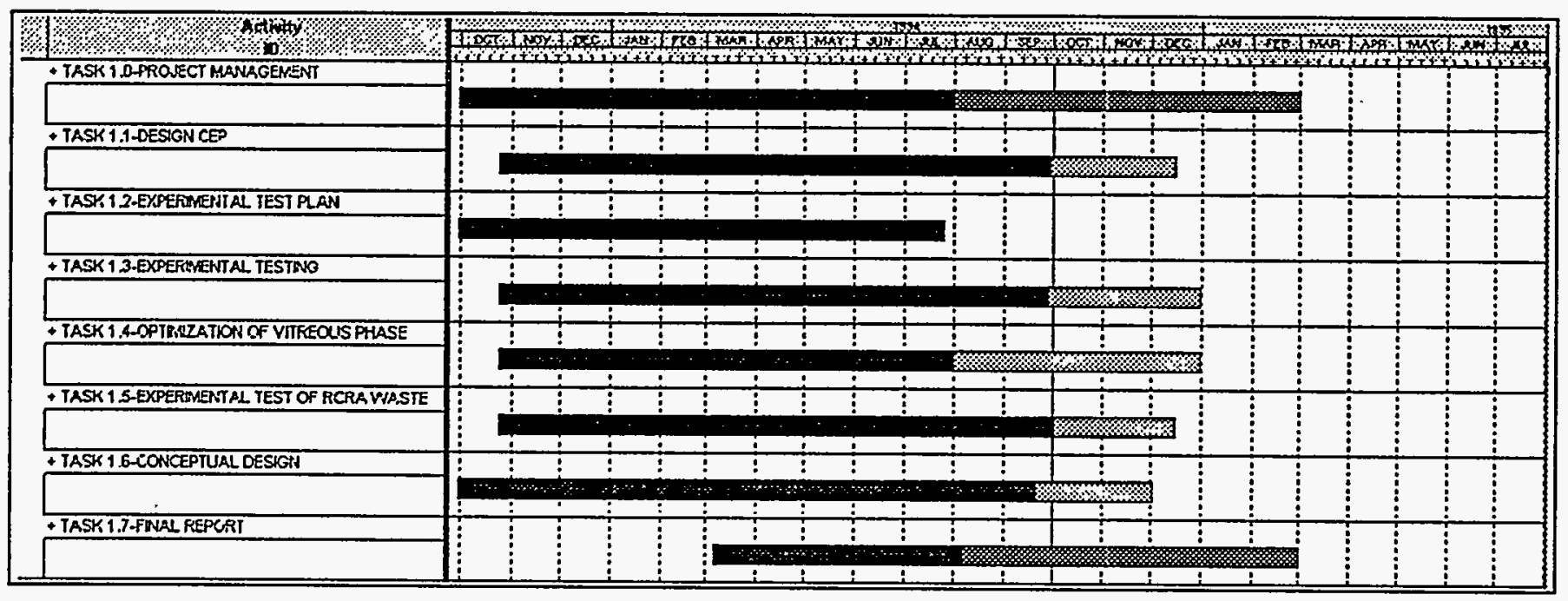

\section{OBJECTIVES}

The contract was conceived to establish the commercial capability of Catalytic Extraction Processing (CEP) to treat contaminated scrap metal in the DOE inventory. In so doing, Molten
Metal Technology, Inc. (MMT), pursued the following objectives:

- Demonstration of the recycling of ferrous and non-ferrous metals -- to establish that radioactively contaminated scrap metal can be converted to high-grade, ferrous and 
non-ferrous alloys which can be reused by DOE or reintroduced into commerce.

- Immobilize radionuclides -- that CEP will concentrate the radionuclides in a dense vitreous phase, minimize secondary waste generation and stabilize and reduce waste volume.

- Destroy hazardous organics -- that CEP will convert hazardous organics to valuable industrial gases, which can be used as feed gases for chemical synthesis or as an energy source.

- Recover volatile heavy metals -- that CEP's off-gas treatment system will capture volatile heavy metals, such as mercury and lead.

- Establish that CEP is economical for processing contaminated scrap metal in the DOE inventory -- that CEP is a more cost-effective and, complete treatment and recycling technology than competing technologies for processing contaminated scrap.

\section{BACKGROUND INFORMATION}

\section{Technology Overview}

CEP is an innovative and proprietary technology that allows organic, organometallic and inorganic waste streams to be recycled into useful resources of commercial value. At the core of CEP is a liquid metal bath which acts as a catalyst and solvent in the dissociation of the feed and the synthesis of products. Upon introduction to the bath, feeds dissociate into their constituent elements and go into metal solution. Once in this dissolved state, addition of co-reactants enables reformation and partitioning of desired products.
The CEP process can be conceptually divided into two stages.

- Catalytic dissociation and dissolution: The catalytic effect of the molten metal bath causes complex compounds in the feed to be dissociated into their elements, which are readily dissolved in the metal bath. These soluble elements form dissolved intermediates.

- Product synthesis: Through the addition of select co-reactants or by controlling operating conditions, the dissolved elemental intermediates can be reacted to form desired products of commercial value. These reactions are driven by thermodynamic forces.

In order to demonstrate the reaction pathway in the CEP system, consider the case of the introduction of an organic feed, such as the type commonly contaminating scrap metal, into a molten metal bath. The organic's reaction pathway is essentially dissociation into a dissolved carbon intermediate (C) which can then be selectively reacted with oxygen to form $\mathrm{CO}$. Schematically, the reaction pathway can be depicted as follows:

$$
\text { Feed } \rightarrow \underline{\mathrm{C}} \rightarrow \mathrm{M}_{\mathrm{X}} \mathrm{C} \rightarrow \text { products }
$$

or, taking an organic as the feed and iron as the metal:

$$
\begin{gathered}
\mathrm{C}_{4} \mathrm{H}_{10}+\mathrm{Fe} \rightarrow \\
4 \mathrm{C}+10 \mathrm{H} \rightarrow 4 \mathrm{Fe}_{3} \mathrm{C}+10 \mathrm{Fe}_{3} \mathrm{H} \rightarrow \\
4 \mathrm{H}_{2}+\mathrm{Fe}
\end{gathered}
$$

Under typical CEP operating conditions both solution and reaction thermodynamics are important driving forces for product formation. For example, the production of synthesis gas is due to the selective addition of oxygen and the effectiveness of the dissolved carbon intermediate as a reductant. This phenomena is best illustrated 
by the Gibbs free energy diagram shown in Figure 1. The left vertical axis is the free energy which is plotted versus temperature. Each line on the diagram represents the reaction of an element with oxygen to form an oxide. At any given temperature, the lower a line is on the diagram, the more favorable the reaction is. This diagram, therefore, represents the relative stability of various oxides when other elements are present. Hence, Group VIII and other transition elements are readily reduced to form metal alloys in typical CEP systems and the uniformly reducing environment of CEP can be maintained through the reaction of carbon with oxygen to form carbon monoxide.

As indicated, this diagram is for pure elements and their oxides. It shows, however, the general trends for reduction/oxidation reactions in CEP and demonstrates the flexibility which can be

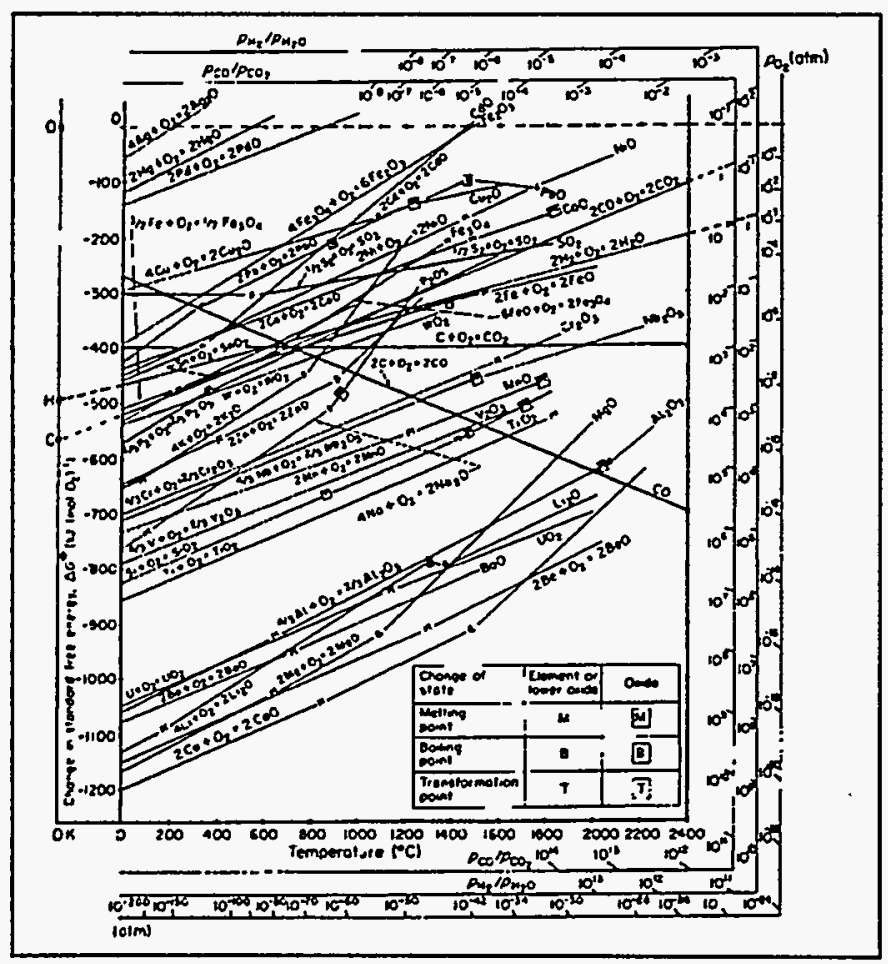

Figure 1. Gibbs Free Energy Diagram for Oxides achieved through select reactant addition and operating parameter manipulation. MMT bases actual thermodynamic predictions upon the activities of species in metallic and oxide solutions and has developed proprietary in-house equilibrium and non-equilibrium models to predict reactant and product behavior.

The importance of the metal bath as a solvent is demonstrated by considering the following competing reaction pathways upon injection of an organic feed into an iron bath:

$$
\begin{gathered}
2 \underline{\mathrm{C}}+\mathrm{O}_{2}(\mathrm{~g}) \rightarrow 2 \mathrm{CO}(\mathrm{g}) \\
2 \mathrm{Fe}(\mathrm{l})+\mathrm{O}_{2}(\mathrm{~g}) \rightarrow 2 \mathrm{FeO} \\
\mathrm{FeO}(\mathrm{l})+\underline{\mathrm{C}} \rightarrow \mathrm{CO}(\mathrm{g})+\mathrm{Fe}
\end{gathered}
$$

As outlined in Figure 1, thermodynamic forces favor the formation of carbon monoxide (CO) over iron oxide ( $\mathrm{FeO})$. The rate of these three reactions, however, is also dependent on the concentration of the dissolved carbon ([C]). At very low carbon activity, iron oxide will be formed preferentially, while at high carbon concentrations, little, if any, $\mathrm{FeO}$ will be formed. The robust nature of the process is demonstrated by the wide range of operating conditions which favor the formation of carbon monoxide and preclude the formation of an oxidative environment.

A typical CEP integrated facility consists of a feed system, the Catalytic Processing. Unit (CPU) or the reactor holding the liquid metal, followed by a hermetically sealed gas handling train and product recovery systems. All process components and equipment are adapted to chemical plant quality and process standards. Each subsystem can be adapted for the requirements of the feed processed and customer product specifications. For example, a chlorinated waste may not require an extensive metal product recovery system, but may require an $\mathrm{HCl}$ recovery and purification system in the gas handling train. 
MMT is currently designing and constructing multiple CEP facilities, including an on-site closedloop application for the chemical industry and a mixed waste (hazardous and radioactive) waste processing facility.

MMT operates a Recycling-Research \& Development Facility in Fall River, Massachusetts. The facility houses four bench-scale units, four pilot-scale units, seven physical models and a commercial demonstration and prototype unit. This state-of-the-art facility is fully permitted by the Commonwealth of Massachusetts for recycling demonstrations using hazardous and nonhazardous materials as CEP feeds. MMT has received recycling certifications from the Massachusetts Department of Environmental Protection for the processing of RCRA and organometallic feeds and has sold the condensed phase products from this facility.

Bench- and pilot-scale experimental units are used to confirm theoretical modeling predictions, establish product quality, determine appropriate materials of construction, assess design parameters and confirm fundamental process chemistry. Many of these systems, including the Advanced Processing Units (APUs) which are appropriate for small commercial-scale operations, are operated round-the-clock for two- to three-week experimental campaigns. Physical models are used to study fluid dynamics and transport phenomena, reactor flow patterns, unique reactor configurations and final design parameters.

The commercial-scale prototype is used primarily for customer and regulatory demonstrations and establishment of commercial design scenarios. MMT has processed a wide range of hazardous, characteristic and surrogate waste feeds in the commercial prototype. The commercial prototype typically operates roundthe-clock during one-week demonstrational campaigns, which may include several different feed materials. Ongoing demonstrations in Fall River have shown the feed destruction and recycling capabilities of CEP. Specifically, CEP recycles waste into commercially valuable products while consistently achieving DREs $\geq 99.9999 \%$. Trace components measure nondetect to the regulatory limits.

\section{PROJECT DESCRIPTION}

To achieve the objectives set forth in the contract, the scope of work was divided into seven tasks:

1.1 Design CEP system for recycling
contaminated scrap metal

1.2 Formulate an experimental test plan

1.3 Experimental testing of surrogate radionuclide partitioning and bulk solids processing

1.4 Optimization of the vitreous phase

1.5 Experimental testing of RCRA wastes

1.6 Preparation of a conceptual design for a CEP facility for DOE's contaminated scrap metal

\subsection{Preparation of a final report}

Work on the individual tasks is nearly complete. Following contract signing, MMT first applied its proprietary thermodynamic, kinetic, and physical transport models to establish CEP design criteria for optimal processing of scrap metal contaminated with radionuclides and organics. Using equilibrium modeling, the homogeneous reactions occurring within individual phases and at the intra-phase interfaces, particularly with respect to the effect of uranium, plutonium and other radionuclides on the CEP system were researched. Using non-equilibrium modeling, MMT assessed 
ways to enhance decontamination performance, component separation, and recovery potential using multi-phase processing.

Following theoretical analysis and computer modeling, MMT's cadre of physical models were employed to verify predictions of hydrodynamic behavior of the system, including the specialized feeding of bulk solids into the bath. The physical models use water as a surrogate for molten iron (water and molten iron have essentially the same viscosity), and various oils and emulsions were used to simulate CEP's vitreous layer. The volatility of many expected components of DOE's contaminated scrap metal was modeled using dry ice particles in various sizes. Hundreds of physical model experiments were performed under the contract, and provided valuable information for use in designing the hot metal experiments and their associated reactor geometries.

Molten metal systems used in service to the contract ranged in size from small bench-scale units employing five pounds of metal, to large demonstration-scale experiments in a unit holding six thousand pounds of molten metal and ceramic. The normal course for the investigation was to verify initial chemistry on the bench-scale with a minimum number of process variables, and then proceed through pilot- to demonstration-scale systems to gradually introduce increasing levels of complexity into the equation.

As described in the contract statement of work, the actual experimental progression was well defined by the tasks set forth. Experimental verification of the ability of system engineers to set the process variables to effect partitioning of radionuclides to targeted phases was proven. Since uranium and the transuranic elements were specifically called out in the SOW, and earlier work predicted oxidation of those elements and their eventual inclusion in the ceramic phase, the work progressed toward the optimization of the chemistry of the ceramic, to provide a stable, durable and predictable form for disposal or reuse. Shifting focus to the hazardous components of the subject contaminated scrap metal, the statement of work contained a series of efforts designed to verify CEP's ability to destroy the hazardous portion of the waste, and pave the way for future delisting efforts.

The combined results of the theoretical efforts and the experimental campaign served to inform a conceptual design for a facility to recycle contaminated scrap metal -- to produce decontaminated metal for re-use within the DOE complex, a syngas with significant fuel value and a ceramic product containing any uranium and transuranics in a durable final form.

\section{RESULTS}

Before designing the experiments to verify CEP's applicability to contaminated scrap metal, MMT undertook an extensive literature search to uncover previous work in related fields which could inform the experiments. Previous results reported in the literature using melt refining techniques with contaminated metals demonstrated that uranium and plutonium can be selectively removed from the metal phase and concentrated in a separable, vitreous oxide phase. Residual concentrations of $10 \mathrm{nCi}$ of such radioactive components had been achieved using the vitreous phase as the sole oxygen source to partition oxidized radioactive components from mild steel, stainiess steel, nickel, copper and aluminum.

It was anticipated that CEP would offer superior capabilities to those of melt refining. Specifically, since CEP allows for co-feeds, such as oxygen, to be injected into the molten metal bath, the system provides for greatly enhanced oxidation of the radioactive components. In contrast, in melt refining, the vitreous phase is the only source of oxygen. Further, turbulence caused 
by gas injection into the CEP bath facilitates mass transfer, leading to active partitioning of radionuclides.

MMT designed a series of bench scale experiments using radioactive surrogate materials to demonstrate the oxidation and partitioning of the radionuclides between the metal and vitreous phases and to identify and optimize the effect of operating conditions on partitioning. The benchscale experiments were followed by experiments

' on pilot-scale (250\# metal bath) and demonstration-scale $(2,000 \#$ and $6,000 \#$ metal baths). Hafnium was selected as the radioactive surrogate material due to its similarities in thermodynamic behavior (Figure 2) and physical properties (Table 1) to uranium. Zirconium, although similar to uranium in the thermodynamic properties, was not chosen as the primary surrogate material because of its significantly lower density, but was actually used as a feed material in several experiments and was also proven to effectively partition to the ceramic phase.

The experimental design parameters evaluated were metal system, gas environment and ceramic phase composition. Radioactive surrogate partitioning was measured using neutron activation analysis (NAA) for non-destructive trace analysis. The hafnium LDL was $0.2 \mathrm{ppm}$ in iron and $2 \mathrm{ppm}$ in nickel. X-ray fluorescence (XRF) was used for analysis of the vitreous phase composition. Metal samples were taken at different positions in the metal bath to ensure uniform concentration. The contract objective was to demonstrate uniform metal decontamination above $98 \%$. In addition, backscattered electron imaging and $\mathrm{x}$-ray analysis were used to investigate the nature of the capture and stabilization of the radionuclide surrogate in the vitreous phase.

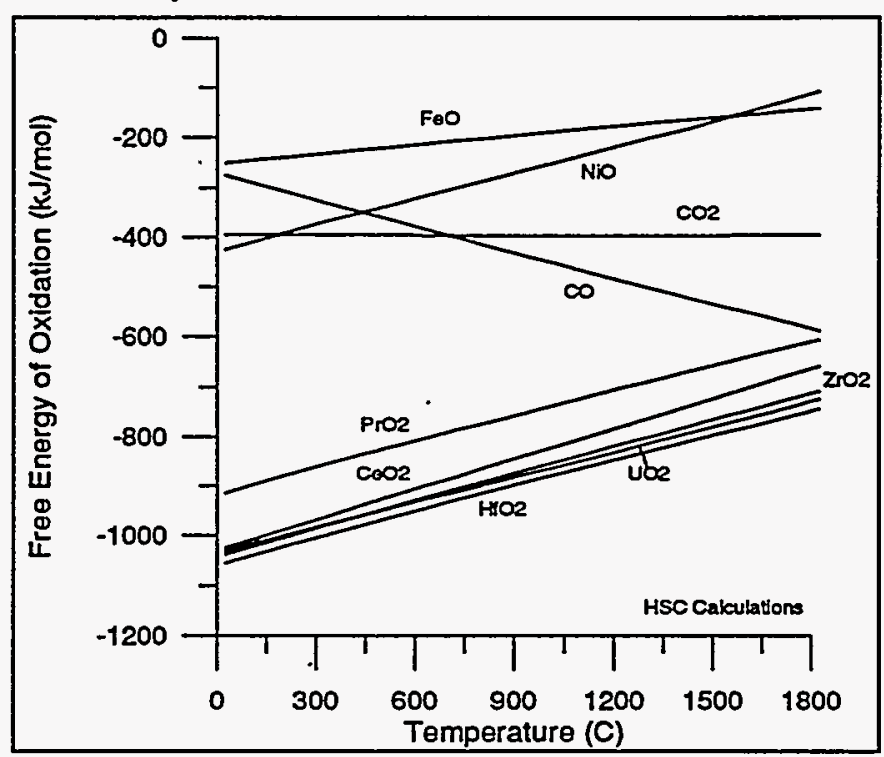
Figure 2. Identification of
Radionuclide Surrogate

Table 1. Physical Properties of Uranium and Surrogates

\begin{tabular}{|c|c|c|c|c|}
\hline \multirow{2}{*}{ Element } & \multicolumn{2}{|c|}{ (oxide } & \multicolumn{2}{|c|}{$4 \mathrm{Metal}$} \\
\hline & mp & Density & rip.p. & Density \\
\hline $\mathrm{U}$ & 2,878 & 10.96 & 1,132 & 19.05 \\
\hline $\mathrm{Hf}$ & 2,758 & 9.68 & 2,227 & 13.31 \\
\hline $\mathrm{Zr}$ & 2,715 & 5.6 & 1,852 & ק.T. \\
\hline $\mathrm{Fe}$ & 1,369 & 5.7 & 1,535 & 7.86 \\
\hline $\mathrm{Ni}$ & 1,984 & 6.67 & 1,455 & 8.90 \\
\hline
\end{tabular}

Average decontamination of the metal exceeded the contract's $98 \%$ objective in all experimental trials with detection of any trace amounts limited by the LDL. Table 2 summarizes the results. V1 refers to aluminosilicate vitreous compositions while $\mathrm{V} 2$ refers to borosilicate vitreous compositions. Exact details of the optimum vitreous phase composition are proprietary. 
Table 2. Radionuclide Partitioning

\begin{tabular}{|c|c|c|}
\hline Metal & Vitreous & Decontamination \\
\hline Phase & & \\
\hline Iron & V1 & $\geq 99.62 \%$ \\
\hline Nickel & V1. & $\geq 99.76 \%$ \\
\hline Iron & V2 & $\geq 99.08 \%$ \\
\hline
\end{tabular}

Samples taken at different positions in the metal bath demonstrate uniform distribution of any trace amounts of hafnium across the metal (Figures $3 \mathrm{a}$ and $3 \mathrm{~b}$ ). This indicates that transport to and incorporation in the oxide phase is very efficient under CEP operating conditions.

Ceramic samples were analyzed using backscatter electron imaging to identify the nature of the radionuclide capture and stabilization in the ceramic phase. This work indicated that operating conditions and vitreous phase composition can affect radionuclide capture and stabilization. Figure 4a shows the backscatter image of a vitreous sample which has separated into hafnium rich and hafnium poor regions. This is in contrast to the vitreous sample shown in Figure 4b, where hafnium is uniformly distributed. This is the desired vitreous radionuclide capture and stabilization.

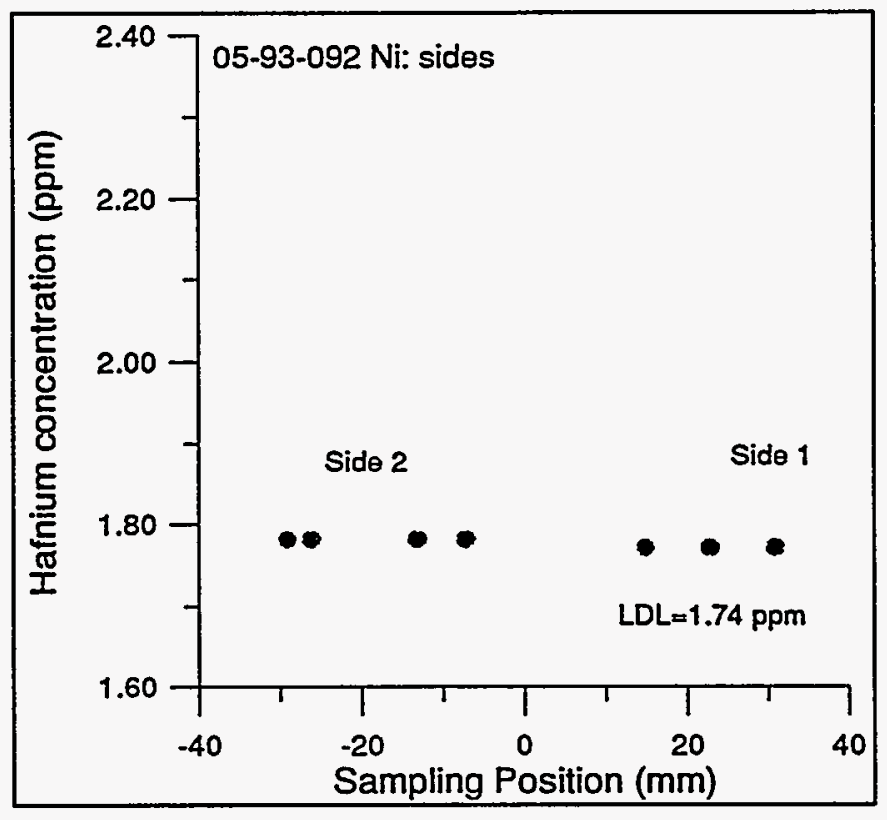

Figure 3a. Sampling across Radius of Metal

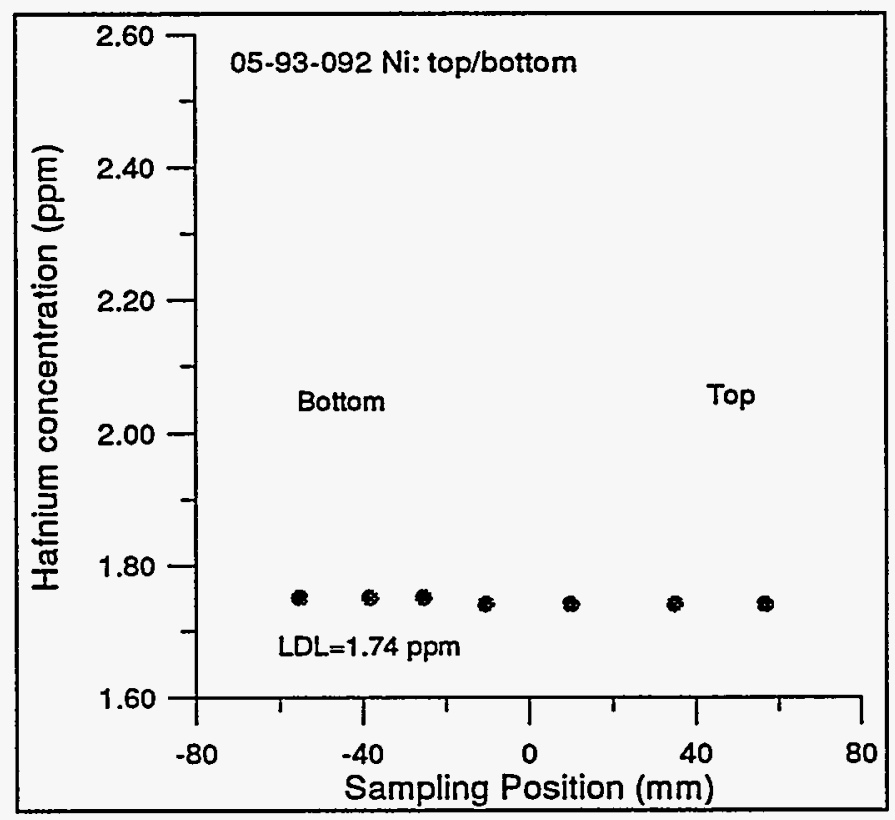

Figure 3b. Sampling from Top to Bottom of Metal 


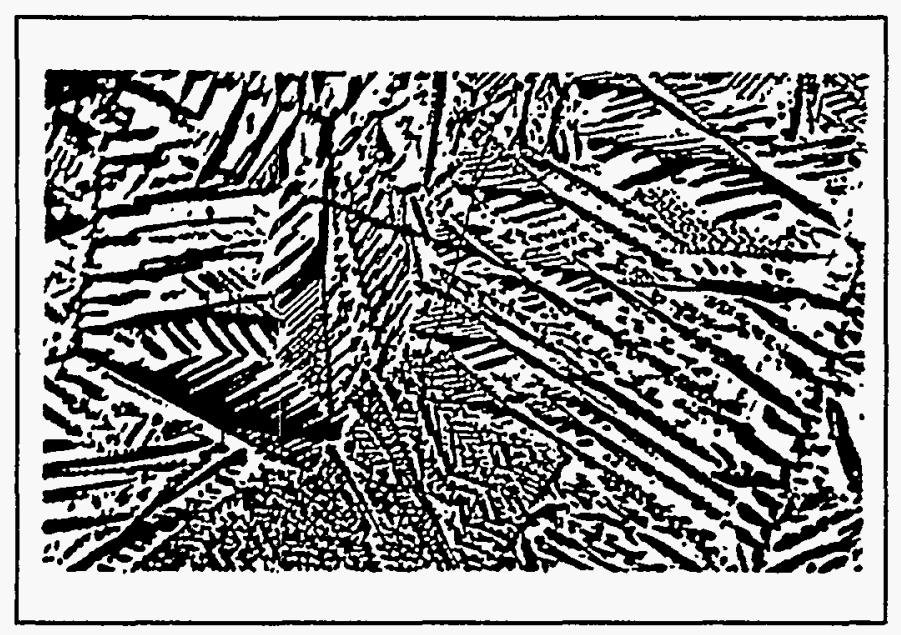

Figure 4a. Backscatter Image: Phase Separation Exhibited

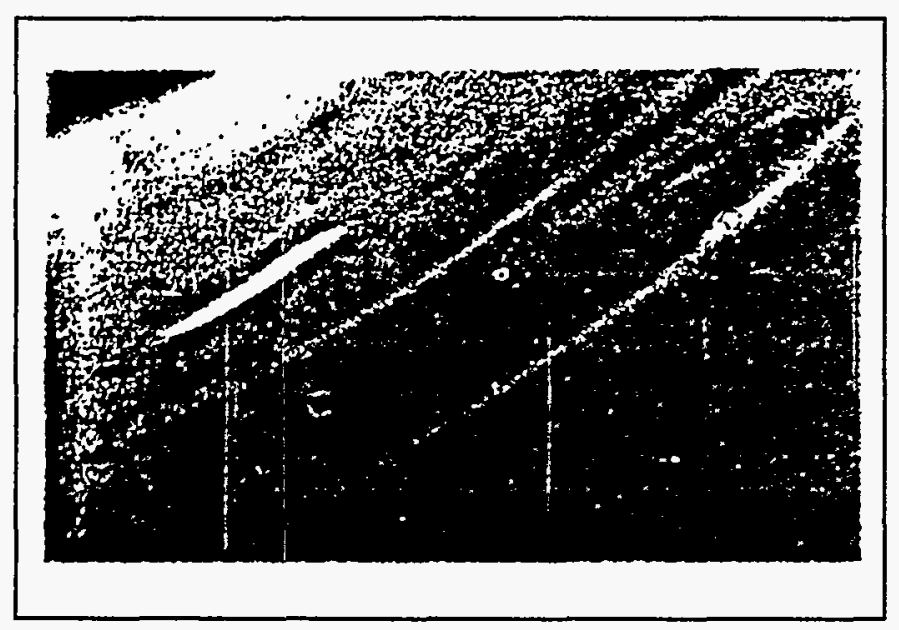

Figure 4b. Backscatter Image: No Phase Separation Exhibited

The investigation of the destruction capabilities of RCRA components of contaminated scrap metal feeds has been well proven during the experimental campaign of this contract. MMT brought to the contract a solid foundation of understanding of the behavior of halogenated feeds in CEP, and proceeded to optimize the chemistry of the system for the feeds anticipated.
Efforts began on bench-scale apparatus, and subsequent prototype trials validated bench-scale results. Gaseous product generation utilizing an iron bath was demonstrated on a demonstrationscale prototype. Chlorinated waste feed surrogates and listed chlorinated waste streams were processed. Halogenated streams processed include contaminated metal components (including some chlorinated plastics) and RCRA-listed streams K019, K020 (heavy residuals from ethylene dichloride and vinyl chloride production) and F024 (chlorinated aliphatics). Chlorine partitioning as anhydrous hydrogen chloride and iron chloride were consistent with thermodynamic predictions and bench-scale data. Hydrocarbon components of the feed were converted to commercial-grade synthesis gas.

Throughout the demonstration-scale CPU and gas handling unit there are 2,000 monitored variables and 900 control loops linked into the computerized monitoring and control modules. Numerous sampling ports throughout the gas handling train enable full characterization of the product gas quality. Summa canister analysis is performed to enable third-party analysis down to ppb levels via established EPA methods. Mass spectrometer samples are drawn on-line and gas composition measurements are taken every twenty seconds for feed-back process control.

Analysis of CPU off-gas product quality indicates that DREs $\geq 99.9999 \%$ are achieved for all feeds (Table 3). Chlorinated aromatics, plastics and straight-chain chloro-organics have been successfully converted to synthesis gas, ceramic products and hydrogen chloride. Data is also shown for CEP of aromatic species and organically-bound nitrogen to demonstrate the high DREs achievable for complex compounds and the preclusion of $\mathrm{NO}_{\mathrm{X}}$ formation (LDL $<1 \mathrm{ppm}$ ), as confirmed by third-party evaluation. 
Table 3. Halogenated Feeds Processed at Demonstration Scale

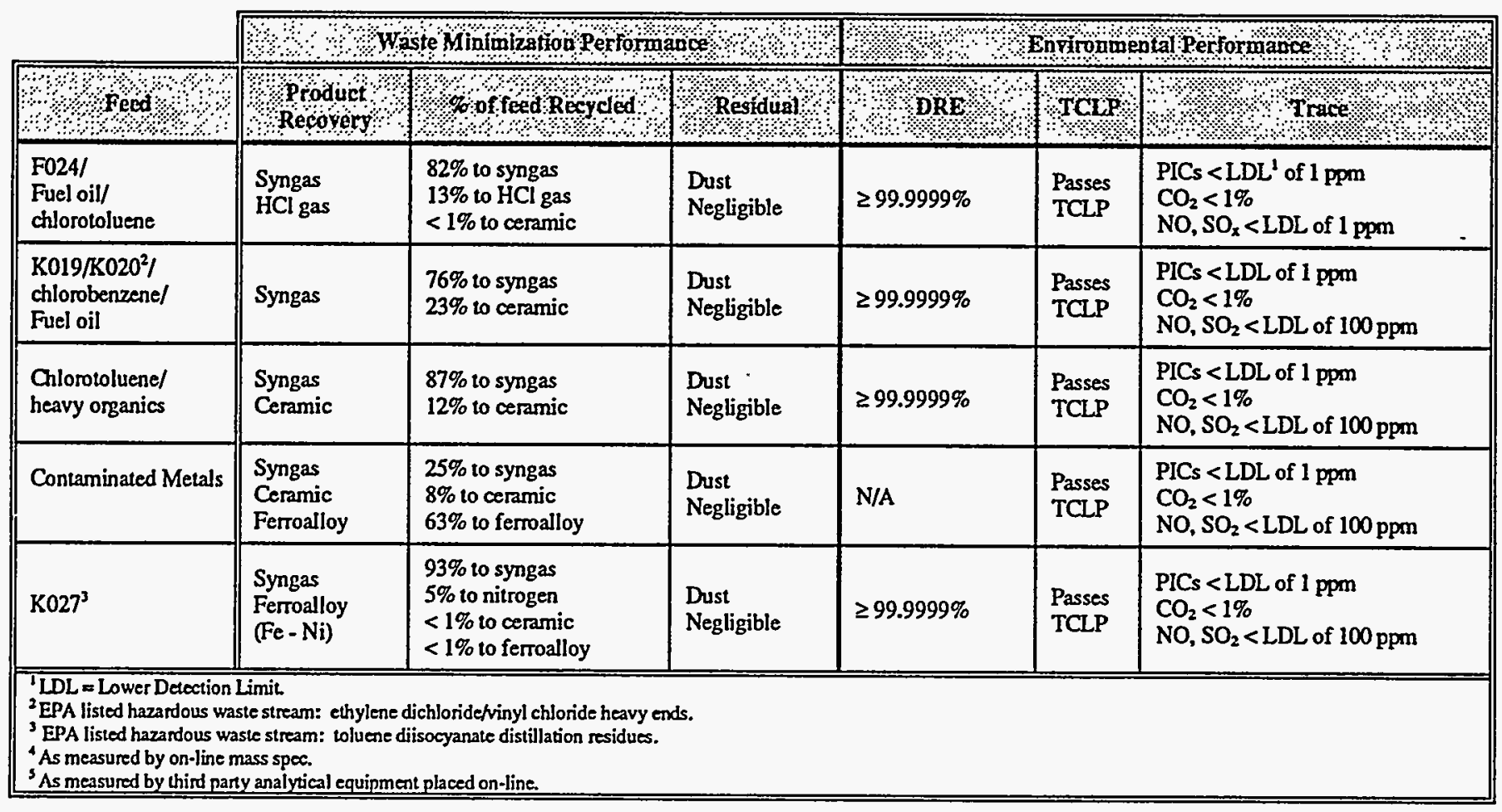

A description of the demonstration-scale processing of RCRA waste F024 exemplifies prototype operations at MMT's Recycling-R\&D Facility. The chlorinated waste mixture $(17.6 \%$ Cl) shown in Table 4 was fed to the CPU. Oxygen was co-fed as a reactant to form $\mathrm{CO}$ and natural gas was fed as a tuyere coolant. An iron bath $(2.5$ ${ }^{w t} \%<[C]<3.0 \mathrm{wt} \% ; 2,600^{\circ} \mathrm{F}<\mathrm{T}<2,750^{\circ} \mathrm{F}$ ) with a ceramic phase was employed.

\section{Table 4. F024 Chlorinated Waste Feed Composition}

\begin{tabular}{|l|c|}
\hline Feed Component & Approximate $\%$ of $\%$ \\
\hline $\begin{array}{l}\text { F024 (RCRA chlorinated } \\
\text { aliphatic waste) }\end{array}$ & 21.6 \\
\hline Fuel Oil & 63.6 \\
\hline Chlorotoluene & 5.0 \\
\hline Chlorobenzene & 9.8 \\
\hline
\end{tabular}

\section{Table 5. Gas Product Composition from Chlorinated Waste Processing}

\begin{tabular}{|l|c|c|}
\hline Gas Product & Approx & Approx \\
\hline Component & Mol\% & Wt\% \\
\hline \hline Hydrogen, $\mathrm{H}_{2}$ & 47 & 6 \\
\hline Carbon Monoxide, $\mathrm{CO}$ & 50 & 86 \\
\hline Hydrogen Chloride, $\mathrm{HCl}$ & 3 & 7 \\
\hline \hline \multicolumn{2}{|l|}{$\begin{array}{l}\text { Carbon Dioxide, } \mathrm{CO}_{2}, \text { concentrations were < } 1 \mathrm{~mol} \% ; \\
\text { Gas compositions based upon Ar tracer gas }\end{array}$} \\
\hline
\end{tabular}

The product gas composition, given in Table 5, shows the generation of products, synthesis gas and anhydrous $\mathrm{HCl}$, from the chlorinated wastes. Material balance closure on the major feed constituents, $\mathrm{C}, \mathrm{H}$ and $\mathrm{O}$, was $94.5 \%, 100.1 \%$ and $103.6 \%$, respectively.

The product gases were extremely pure. Total hydrocarbon concentrations $\left(\mathrm{C}_{2}+\right)$ in the off-gas were $\leq 5 \mathrm{ppm}$. Methane concentrations were 
consistent with thermodynamic predictions $(\approx 50 \mathrm{ppm}) . \mathrm{NO}_{\mathrm{x}}$ and $\mathrm{SO}_{\mathrm{x}}$ were not detected to the on-line lower detection limit of $3 \mathrm{ppm}$ and 1 $\mathrm{ppm}$, respectively. Summa canister samples from the off-gases, subjected to EPA TO-14 analysis, demonstrated destruction and removal efficiencies (DREs) of the principal organic hazardous constituent (POHC) $\geq 99.9999 \%$ (Table 6).

\section{Table 6}

DREs Based on Multiple Chlorinated Organic Feed Constituents for CEP of F024

\begin{tabular}{|l|c|}
\hline Feed Constituent & DRE \\
\hline \hline $1,1,2$-Trichloroethane & $\geq 99.9999 \%$ \\
\hline Chlorobenzene & $\geq 99.9999 \%$ \\
\hline $\begin{array}{l}1,1,2,2- \\
\text { tetrachloroethane }\end{array}$ & $\geq 99.9999 \%$ \\
\hline Trichloroethene & $\geq 99.9999 \%$ \\
\hline $\begin{array}{l}\text { Note: Data based upon the consistent results of } \\
10 \text { different samples }\end{array}$ \\
\hline
\end{tabular}

The demonstration-scale data verifies the thermodynamically-predicted partitioning of chlorine in an iron bath and establishes CEP's ability to generate high-quality products from chlorinated RCRA wastes. Chlorine was successfully recovered as anhydrous $\mathrm{HCl}$. The feed conversion exceeded $99.9999 \%$ and the product gases contained no undesired species. The ceramic phase formed a non-leachable (TCLP), durable glass product.

CEP reaction pathways, combined with the uniform and highly reducing environment maintained over a wide range of operating conditions, preclude the formation of dioxins, furans and other undesirable by-products. Research suggests that all of the following conditions must be present to promote the formation of dioxin: excess free $\mathrm{O}_{2}\left(\geq 10^{-3} \mathrm{~atm}\right.$ partial pressure), the presence of aromatic precursors, sufficient residence time in the temperature range around $300^{\circ} \mathrm{C}\left(572^{\circ} \mathrm{F}\right)$, and the presence of heterogeneous catalytic surfaces (e.g., particulates). $\mathrm{i}_{\mathrm{i}, \mathrm{i}, \mathrm{iii}, \mathrm{iv}}$ These essential conditions for formation of dioxins are either inherently absent or can be minimized through appropriate design and operation of the CEP system.

Extremely low oxygen concentrations in the CEP off-gas will inhibit the formation of dioxins. Oxygen partial pressure is continuously monitored in the prototype demonstration unit and is not detected. Thermodynamic evaluation of CEP reaction scenarios shows that partial pressures of $\mathrm{O}_{2}$ can approach $10^{-15} \mathrm{~atm}$.

CEP solution chemistry can ensure that all species pass through a dissolved intermediate and preclude the formation of aromatic precursors. Table 4 shows that Destruction and Removal Efficiencies (DREs) are greater than $99.9999 \%$ for a wide variety of aromatic feeds, isocyanates, chlorinated plastics (PVC and polystyrene) and chlorinated solvents. The DRE data is based upon third-party summa-canister analysis using TO-14 analysis.

\section{FUTURE WORK}

The optimization of Catalytic Extraction Processing for the recycling of contaminated scrap metal by the DOE will require further efforts in four areas: bulk solids addition, delisting of the product phases, separation of chemically similar metals and progression of the conceptual design. 


\section{REFERENCES}

1 Altwicker, E.R., Xun, Y., Milligan, M.S., Dioxin Formation Over Fly Ash: Oxygen Dependence, Temperature Dependence and Phase Distribution. The Isermann Dept. of Chemical Engineering, Rensselaer Polytechnic Institute, Troy, NY, 1994.

"Yamamoto, T. and Inoue, S., Chemosphere, Vol. 20, Nos. 10-12, pp. 1915-1920, 1990.

iii Vogg, H., Stieglitz, L., Chemosphere, Vol. 15, Nos. 9-12, pp. 1373-1378, 1986.

"Stieglitz, L., Zwick, G., Beck, J., Roth, W., Vogg, H., Chemosphere, Vol. 18, Nos. 1-6, pp. 1219-1226, 1989. 